\title{
Obstacles of Implementing Industry 4.0 in Nepalese Industries and Way-Forward
}

\author{
${ }^{1}$ Niranjan Devkota, ${ }^{1}$ Sharad Rajbhandari, ${ }^{1}$ Udaya Raj Paudel, ${ }^{1}$ Seeprata Parajuli \\ ${ }^{1}$ Quest International College, Pokhara University, Gwarko, Lalitpur, Nepal \\ niranjandevkota@gmail.com, frndshrd@gmail.com, udayapaudel7@gmail.com, \\ pseeprata@gmail.com
}

\begin{abstract}
Industry 4.0 is buzzword in recent years and has become a topic of growing importance. It is a new technical framework that has been widely debated and studied and is likely to eventually constitute a fourth industrial revolution because it provides significant progress relevant to intelligent and potential industries in the market. As Nepal has introduced open policies for improving trade conditions in the mid-1980s, industries have to be competitive and capable enough to sustain themselves in such open policies. Such, dependencies can be minimize, and could only be possible, through the increasing the competitiveness of Nepalese industries with the help of use of new technologies. In such context, Nepalese industrial readiness for industry 4.0 is important topic to discuss. This study aims to identify the obstacles of implementing industry 4.0 in Nepalese Industries lies within 3 industrial estates of Kathmandu Valley i.e. Balaju, Patan and Bhaktapur industrial estates. Data has collected data from all 287 running industry from all three industrial estates with the help of questionnaire through respondent interview using KoBo Collect Toolbox. Our study finds that half of the industries (49\%) face hurdles while adopting new technologies. Among them, the major hurdles are lack of infrastructure, lack of skilled manpower, lack of capital, poor implementation of policies. Among two third of the respondents think obstacles in implementing industry 4.0 is manageable. Political support, improvement in implementation mechanism and long term strategy are key factors that support industries to invest in new innovative technologies.
\end{abstract}

Keywords: Industrial Estates, Industry 4.0, Obstacles, Kathmandu Valley, Nepal

\section{How to Cite:}

Devkota, D., Rajbhandari, S., Paudel, U. R., Parajuli, S. (2021). Obstacles of Implementing Industry 4.0 in Nepalese Industries and Way-Forward. International Journal of Finance Research, 2(4). 286 - 295. DOI: https://doi.org/10.47747/ijfr.v2i4.488

\section{Introduction}

In recent years, the word "Industry 4.0" has become a topic of growing concern (Morrar et al, 2017; Kamble \& Gunasekaran, 2018; Rajbhandari et al., 2020). This idea was first published in the German government in November 2011 as a part of a High Technology Strategy Plan for 2020 (Zhou, Liu, \& Zhou, 2016). The global industrial scenarios are changing dramatically in recent years, only due to the innovation and developments in manufacturing 
processes (Yang \& Shyu, 2009; Pereira \& Romero, 2017). Over recent years, numerous new global trends have arisen with the growing advancement over production processes and technologies (Mourtzis, 2020). Industry 4.0 can be tentatively linked to three revolutions in recent centuries which are the latest transformative productivity shifts arising from multiple technological developments (Schmidt, Möhring, Härting, Reichstein, Neumaier, 2015). The heart of every industrial revolution is increased productivity (Rajbhandari et al., 2020).

Industry 4.0 is a new technical framework that has been widely debated and studied and is likely to eventually constitute a fourth industrial revolution because it provides significant progress relevant to intelligent and potential industries in the market (Schneider, 2018). The new concept of industry 4.0 is the cornerstone to new industrial model that covers a range of industry technologies including cyber-physical systems (CPS), the Internet of things (IoT), Internet of services (IoS), robots, big data and cloud computing (Schuh et al., 2014). The new approach brings digital and physical environments together through CPS technologies, opening up a range of potential markets that will allow the businesses embracing the new production model to increase productivity and efficiency (Zhou et al., 2016). Industry 4.0 has tremendous potential, and through the structural change in terms of organization and market modals and manufacturing technologies, it will generate a variety of economic and social opportunities (Kagermann, Wahlster, \& Helbig, 2013).

Nepal introduced open policies for improving trade conditions in the mid-1980s, reducing external dependence and creating jobs, but failed to achieve the aforementioned aims. Nonetheless, that dependence on foreign markets to satisfy the rising need for capital goods and intermediate inputs was an obstacle to the growth of manufacturing because of the capital-intensive existence of the IS industries. Since late 1950s, Nepal has carried out regular economic plans (Rajbhandari et al, 2020). However, the low level of mobilization of domestic resources, unsatisfactory external aid payments, and poor project management were primarily attributed to low production capacity, although government spending has been growing (Mainali, 2017; B. K. et al., 2020). Nepal is $119^{\text {th }}$ out of 135 countries in the Sustainable Industrial Performance Index (CIP). According to Economic Survey (2018) the number of industries was 7832 .

Out of these registered industries, Two-thirds of the industries are recorded in Bagmati Province and lowest in Karnali Pradesh until mid-March of the FY 2018/19. This evidence states the slow pace of industrial development in Nepal as well as the weak situation of the industrial sector in Nepal. However various liberalization steps have been introduced, including elimination of import licenses, full Nepalese rupees convertibility, the opening of joint venture financing, FDI arrangement and one window scheme, new foreign Investment, and Technology Transfer Act, etc. This cause increased in dependency of Nepal. Until now, large-scale trade has been owned by foreigners, primarily Indians. Dependency on other nations is like a huddle for Nepal's overall development. Thus, these dependency should minimize and this could be possible through the increasing the competitiveness of Nepalese industries with the help of use of new technologies. From all above evidence, we acknowledge that Nepal's industries are not so much developed. Thus, concerning all rationale in this study is focused to measure industrial readiness for industry 4.0.

This study is further organized as: second section includes methods used, in section three results of the study are highlighted and section four concludes the study. 
Vol. 2 No. 4 December 2021

\section{Literature Review}

The popular phrase for defining developments towards digitization and automation of the manufacturing environment is Industry 4.0 in recent years. This definition has still not earned much attention in the building industry despite its potential advantages with regard to improvements in productivity and quality. The fact that the far-reaching consequences of the increasingly digital and automated fabrication atmosphere are still relatively unexplored is the basis of this development(Nagy, Oláh, Erdei, Máté, \& Popp, 2018; Oesterreich \&Teuteberg, 2016). Similarly, Oesterreich \& Teuteberg(2016) has mentioned that the adverse effects of wasteful and industrial use and output practices are impossible to manage in a competitive business setting. It calls for significant asset performance improvement across the worldwide economy. Several companies have therefore found opportunities to recycle goods or services and have the quality of the material and power supplies recovered over a longer time period.

In case of German manufacturing industry, established producers have acknowledged that consumers are not prepared to pay high prices for improved quality. As a result, most companies in Germany manufacturing industry customize their production to custom goods and rapidly become marketable. With the advantages of new manufacturing techniques such as Agile Production and Mass Customization, manufacturing companies become interconnected networks, where their key competences are fused together(Keller, Rosenberg, Brettel, \& Friederichsen 2014). More specially, Erol et al.(2016); Horváth \& Szabó (2019)observed that manufacturers are currently facing significant problems with respect to technological technologies such as the Internet of Things, Cyber Physical Systems or Cloudbased Manufacturing-often referred to as Industry 4.0. Eventually, the growing difficulty at all layers of organizations creates uncertainty as to their respective organization, technologies and plans for developing them. Likewise in the study of Horváth \& Szabó(2019), they explained that the today's global economic landscape produces an adverse situation for the operation of economic systems.

With the path and volatile growth of the model set, the recent financial and financial crisis destabilized the global economy and demonstrated a lack of perspective. Countries also pursued a more sustainable model of economic growth to permit them to enter a new path of development, opening up wider opportunities for social well-being and development. This generation is the generation of industry which has significant importance of manufacturing. Industrial revolution like industry 1.0, 2.0 and 3.0 are still arising in industries. The disparity between supply and demand within distribution chains is a constant problem for manufacturing companies (Horváth \& Szabó, 2019). Similarly, Oesterreich \& Teuteberg(2016) observed the present situation of technologies related to industry 4.0 and to present the different angle view for its implementation. Understanding of relationship between industry4.0 and sustainable manufacturing contributed by the development of the industry 4.0 through the sustainable manufacturing could helpful for industries which are adopting innovative industrial technologies(Machado, Winroth, \& Ribeiro da Silva, 2019).

Similarly,Erol et al.(2016) observed the readiness of manufacturing industry with regard to implementing industry 4.0 which is significant for government as well as industry as well to implement new innovative technologies. Technologies are rapidly changing and innovating, reason behind the adaptation of new innovative technologies there are several driving forces. Müller et al.(2018) observed opportunities and challenges which are taken as fostering factor 
for implementation of industry 4.0 considering different aspect of firm's characteristics such as size, role as provider and user and sector. Though there are also several barriers for implementing industry 4.0. Raj et al.(2019) examine the barriers to implement industry 4.0 in context of developing and developed country which contributes towards managers, government for develop policy as well as students for future research in field of industry 4.0. Industry 4.0 in 2019 relies on eight enabling technologies only(Paulo, Pacchini, Cezar, Facchini, \& Mummolo, 2019).

\section{Research Methods}

\subsection{Study Area and Population}

The area of this study was Kathmandu valley of Bagmati Province, Nepal. Kathmandu valley is situated between $27^{\circ} 32^{\prime} 13^{\prime \prime}$ and $27^{\circ} 49^{\prime} 10^{\prime \prime}$ latitudes north and $85^{\circ} 11^{\prime} 31$ " and $85^{\circ} 31^{\prime} 38^{\prime \prime}$ longitudes to the east and 1300 meters above sea level (Bhandari et al., 2021). The valley covers the entire Bhaktapur district, $50 \%$ of Lalitpur and $85 \%$ of Kathmandu (Pant \& Dongol, 2009; Adhikari et al., 2021). There are three industrial estates in Kathmandu Valley alone industrial estate of Balaju; industrial estate of Patan and industrial estate of Bhaktapur (Devkota et al., 2020). In order to make use of their true potential, these industrial areas require massive infrastructure rework. The use of new technologies in production process was one of the essential subjects. Therefore, these three industrial estates have been chosen by the researcher as study area.

The total area occupied by Bhaktapur industrial estate was 71.28 ropanies and all land was fully developed, where 35 industries were in operation out of 36 . The total area of Patan industrial state was 293 ropanies, 293 of which were well formed ropanies. Similarly, there were73 ropanies covered by the field of operations. There were currently 118 industries within the district, 118 of which were operating. And Balaju Industrial estate has 670 ropanies out of which 540 ropanies were well developed. There were currently 141 industries in the area, 134 of which were operating industries (Industrial District Management, 2018). This three industrial estates include 295 enterprises, 287 of which operating. For our study purpose, number of population was 287 . Thus, we adopted census method to collect data for our study.

\subsection{Research Instrument}

This study is based on survey questionnaire. Questionnaire allows a broad sample of the research population to include abstract and goal information in an attempt to achieve findings that are also worth mentioning (Abawi, 2013). Kobo toolbox was used to hold and fill the questionnaire. After the data was collected it was analyze with the help of tables and charts.

\subsection{Data Collection and Analysis}

Data analysis is a method to put together evidence and data to solve the question of the report. The data analysis deriving from data processing and inferences are another essential aspect of the inquiry and conclusions are made. Two sections of the data study contain descriptive statistics and Readiness index for this study. The data analysis includes industrial readiness index for industry 4.0, factor affecting industrial readiness, obstacles while implementing industry 4.0 and managerial solution related to industry 4.0 practices in Kathmandu valley. 


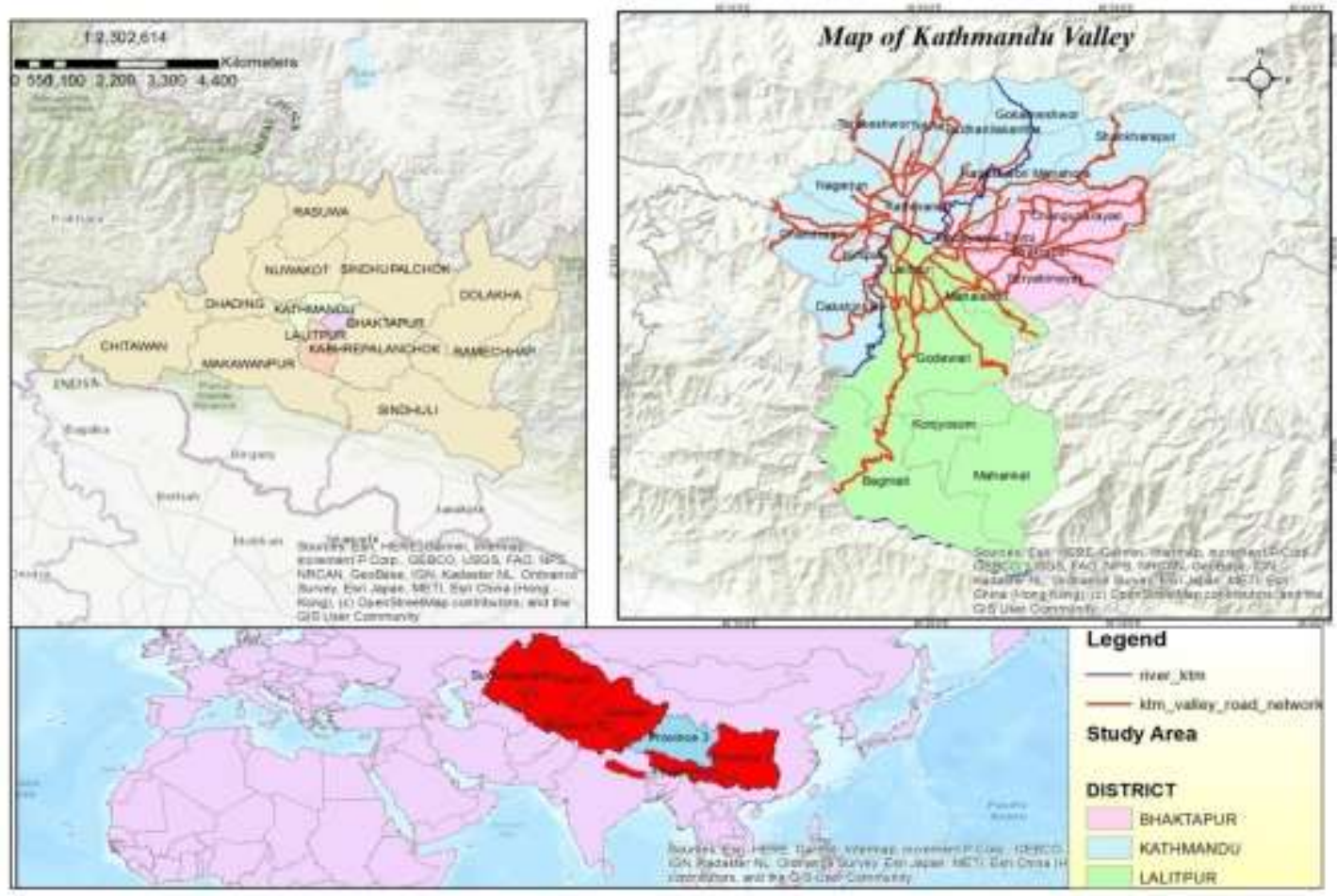

Figure 1: Study Area

The descriptive analysis includes an analysis focused on mean, average, and style and so on. Descriptive research is structured to explain several data properties that are typically analyzed. For the ranking of the readiness level, Readiness degree table was stated, which is developed by (Paulo et al., 2019).

Table 1: Degree of Readiness

\begin{tabular}{|c|l|l|}
\hline Degree of Readiness (DR)-\% & Status & \multicolumn{1}{|c|}{ Characteristics } \\
\hline $0<\mathrm{DR}<10 \%$ & Embryonic & $\begin{array}{l}\text { The firm knows a limited } \\
\text { range of activated } \\
\text { innovations superficially (if } \\
\text { any). }\end{array}$ \\
\hline $10<\mathrm{DR}<25 \%$ & Initial & $\begin{array}{l}\text { Some innovations are known } \\
\text { to the organization but not all } \\
\text { of them can be known. }\end{array}$ \\
\hline $25<\mathrm{DR}<50$ & Primary & $\begin{array}{l}\text { All developments are well } \\
\text { known to the Organization, } \\
\text { but not all have already been } \\
\text { implemented. }\end{array}$ \\
\hline
\end{tabular}




\begin{tabular}{|c|l|l|}
\hline $50<\mathrm{DR}<75 \%$ & Intermediate & $\begin{array}{l}\text { The business understands all } \\
\text { innovations and it started } \\
\text { to be applied. }\end{array}$ \\
\hline $75<\mathrm{DR}<90 \%$ & Advance & $\begin{array}{l}\text { The business has full } \\
\text { understanding and a high } \\
\text { degree of acceptance of all } \\
\text { technology }\end{array}$ \\
\hline $90<\mathrm{DR}<100 \%$ & Ready & $\begin{array}{l}\text { Almost all the activated } \\
\text { innovations are completely } \\
\text { embraced by the } \\
\text { organization. by }\end{array}$ \\
\hline
\end{tabular}

Source: Paulo et al. (2019)

\section{Results and Discussion}

\subsection{Obstacles of Implementing Industry 4.0}

$49 \%$ industries revealed that they have hurdles while adopting new technologies. However, other $51 \%$ of industries were not having any hurdles in adopting new technologies, because of low use or non-use of technologies in industrial process. Figure 3 demonstrates that there are several challenges or hurdle while adopting new technologies. The major hurdles are lack of infrastructure, lack of skilled manpower, lack of capital, poor implementation of policies and others. Figure 3 shows 14\% hurdles arrive due to lack of infrastructure in industries. Similarly, $24 \%$ of hurdles occur due to lack of skilled manpower for operation of new technologies.

Industrial representatives also mentioned that, the challenges or hurdles while adopting new technologies were occurred due to Government agencies like custom, labor union, political parties, pressure group, and local youth clubs. It was observed that almost half of the hurdles were due to government agencies. Similarly, labor unions were also creating hurdle while adopting new innovative technologies. Furthermore, $15 \%$ of challenges occurred due to political parties and remaining $18 \%$ of challenges occurred due to other stakeholders.

\subsection{Managerial Solution for Promoting Industrial Readiness for Industry 4.0}

Among two third of the respondents (71\%) think obstacles in implementing industry 4.0 is manageable. Whereas, $29 \%$ of respondents think they are not manageable because of unanticipated nature of political situation, poor implementation of policies and nonrequirement of innovative technology in their business. Industrial development is the backbone of the economic prosperity of the nation. In developing countries like Nepal, industries are the one of the major source of employment. Thus, developments of industrial areas are essential for the nation. Though there are several challenges while operating industries. Respondents suggests following strategies for industrial development. 


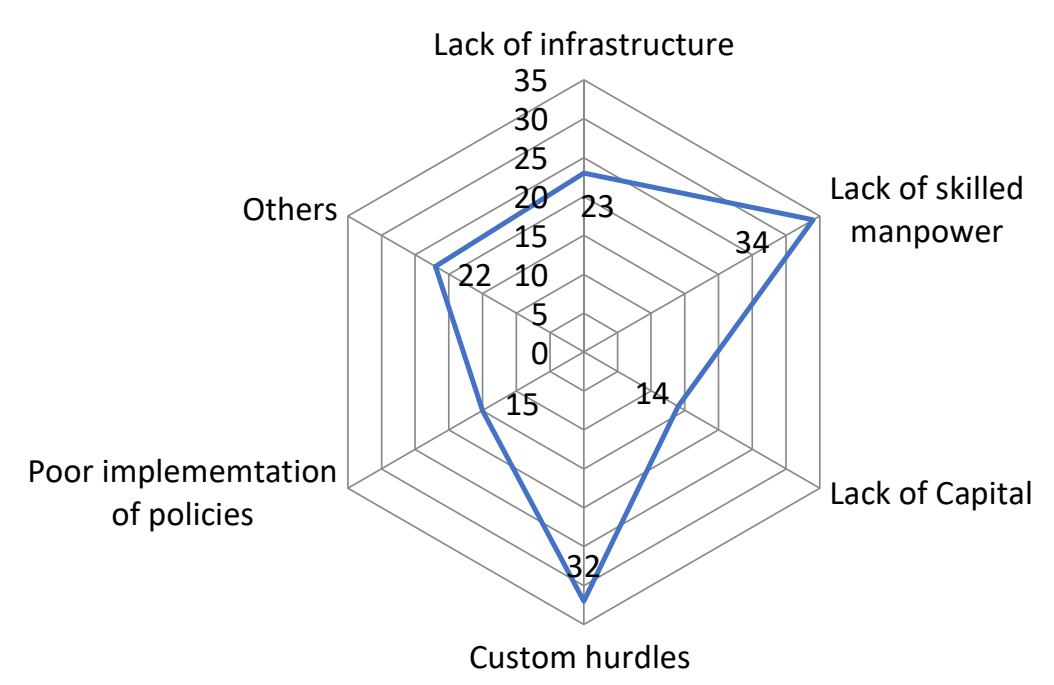

Figure 3: Obstacles of Implementing Industry 4.0

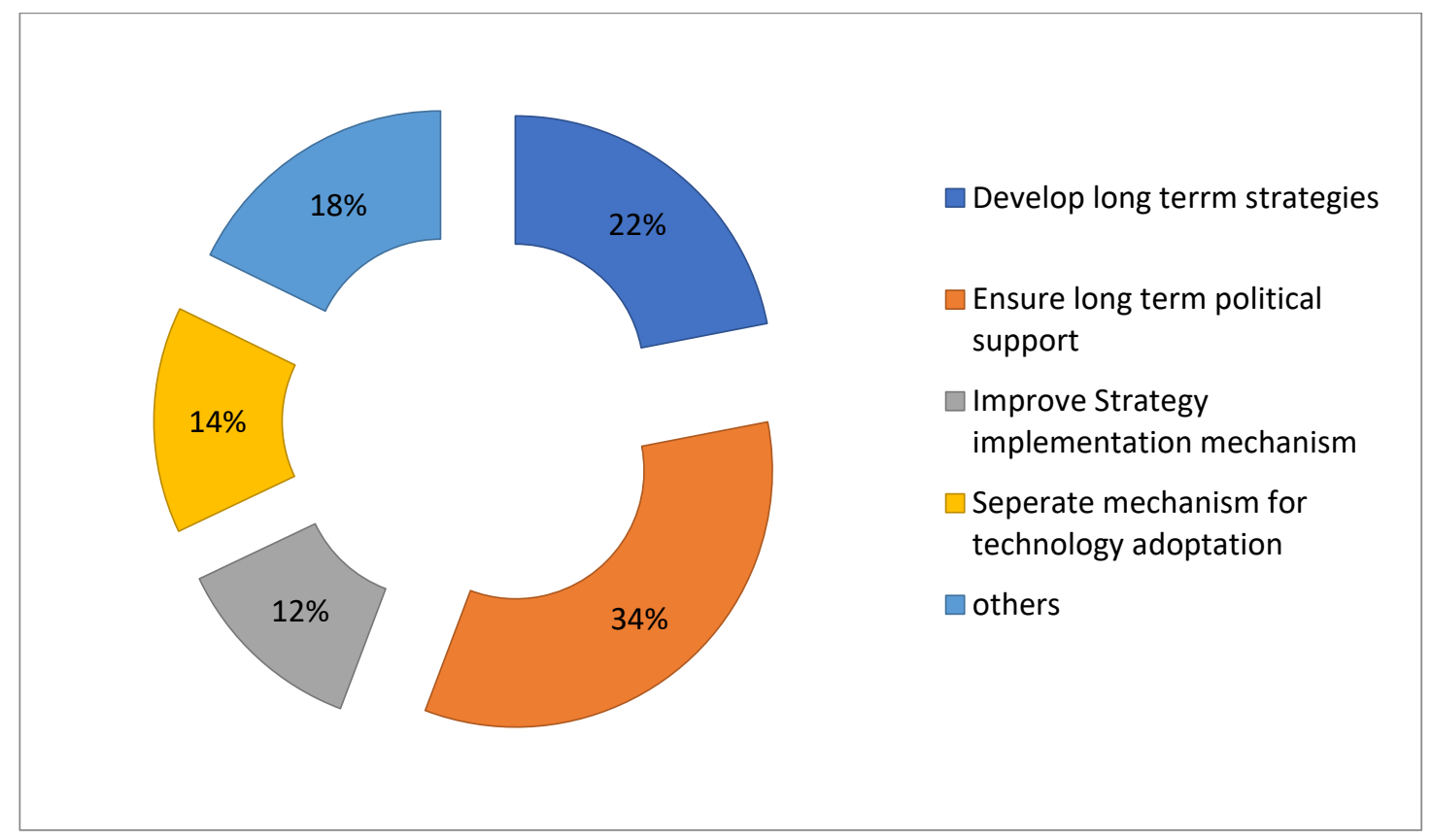

Figure 4: Managerial Solutions

Figure 4 demonstrates strategies that should be implemented for the betterment of industrial sectors. Majority (34\%) of respondents revealed that political support for long term is the key factor that may support them to invest in new innovative technologies. Similarly, improvement in implementation mechanism and long term strategy are other factors that help them to facilitate while adopting technologies. 


\section{Conclusion}

The present study describes the obstacles in adopting new and enabling technologies Industry 4.0 in industries located in three industrial estates of Kathmandu valley. The other aim of the study is to identify managerial implementation for the successful implementation of new technology to enhance industries on the road to industry 4.0. The finding from this study revealed that $51 \%$ industries located in industrial estates are were not having any hurdles in adopting new technologies, because of low use or non-use of technologies in industrial process; however $49 \%$ industries are facing hurdles while adopting new technologies. This study also found that respondents have positive towards promoting industrial readiness for industry 4.0 and $71 \%$ of them think that those obstacles in implementing industry 4.0 is manageable. But, for few respondents, innovative technology in their business is not necessary. Political support (34\%) for long term is the key factor that may support them to invest in new innovative technologies along with improvement in implementation mechanism and long term strategy help industries to adopting technologies enabling towards industry 4.0.

Among the industrial of this study's study area $22 \%$ of industries states that the major problem was poor implementation of formulated policy and regulation. To make more flexible environment for adoption of new technologies, concern stakeholders should focus on improving Strategy implementation mechanism.

Some important findings can be managed in order to enhance Industry 4.0.

1. Improve the strategy implementation mechanism: Among the industrial of this study's study area $22 \%$ of industries states that the major problem was poor implementation of formulated policy and regulation. To make more flexible environment for adoption of new technologies, concern stakeholders should focus on improving Strategy implementation mechanism.

2. Improve Custom Facilities: The major huddles while importing technologies mention by industries is Custom huddles. For the ease of technology implementation government should improve the facility of custom for industries and remove the huddles as much as possible.

3. Develop Separate Mechanism for Technology Implementation: In context of Nepal, industries are still behind the in case of use of innovative technology. For the adoption of technologies in industrial sector concern parties should develop a separate mechanism so that use of technology should ease for industries.

4. Development of Skilled Manpower: This is another major challenge for industries while adopting the new technologies in the organization process. Industries were lacking manpower for operating and service of the new technologies. Therefore, stakeholders should focus on developing require manpower for technology implementation.

\section{References}

Abawi, K. (2013). Data collection instruments (questionnaire \& interview). Geneva: Geneva Foundation for Medical Education and Research.

Adhikari, D. B., Shakya, B., Devkota, N., Karki, D., Bhandari, U., Parajuli, S., \& Paudel, U. R. (2021). Financial hurdles in small business enterprises in Kathmandu 
Valley. Modern Economy, 12(6), 1105-1118.

B.K, A., Devkota, N., Gautam, N., \& Paija, N. (2020). Industry Willingness to Pay for Adequate Electricity Supply: A Discourse on Sustainable Industrial Development. Quest Journal of Management and Social Sciences, 1(2), 251-259.

Bhandari, U., Rana, M., Devkota, N., Parajuli, S., \& Poudel, U. (2021). Status of Professional Skills in MBA Graduates, Its Challenges, and Way forward in Kathmandu Valley: Evidence from Professional Skill Index. International Journal of Finance Research, 2(1), 24-36.

Castelo-Branco, I., Cruz-Jesus, F., \& Oliveira, T. (2019). Assessing Industry 4.0 readiness in manufacturing: Evidence for the European Union. Computers in Industry, 107, 22-32.

Devkota, N., Paija, N., Paudel, U. R., \& Bhandari, U. (2021). Mapping the industries' willingness to pay for unrestricted electricity supply. Environment, Development and Sustainability, 1-17.

Economic Survey. (2018). Economic Survey 2018 / 19. Retrieved from https://www.mof.gov.np/uploads/document/file/compiled\%20economic\%20Survey\% 20english\%207-25_20191111101758.pdf

Industrial District Management. (2018). Memorial,2018/19. Retrieved from http://idm.org.np/

Kagermann, H. (2015). Change through digitization-Value creation in the age of industry 4.0. Management of Permanent Change, $0(0), 23-45$.

Kamble, S. S., Gunasekaran, A., \& Gawankar, S. A. (2018). Sustainable Industry 4.0 framework: A systematic literature review identifying the current trends and future perspectives. Process Safety and Environmental Protection, 117, 408-425.

Mainali, P. K. (2017). Productivity and growth of manufacturing industries in Nepal (Doctoral dissertation, Faculty of Humanities and Social Science of Tribhuvan University).

Morrar, R., Arman, H., \& Mousa, S. (2017). The fourth industrial revolution (Industry 4.0): A social innovation perspective. Technology Innovation Management Review, 7(11), 1220.

Mourtzis, D. (2020). Simulation in the design and operation of manufacturing systems: state of the art and new trends. International Journal of Production Research, 58(7), 1927 1949.

Pant, P. R., \& Dongol, D. (2009). Kathmandu Valley Profile: Briefing Paper. (February).

Paulo, A., Pacchini, T., Cezar, W., Facchini, F., \& Mummolo, G. (2019). Computers in Industry The degree of readiness for the implementation of Industry 4 . 0. Computers in Industry, 113, 103125. https://doi.org/10.1016/j.compind.2019.103125

Pereira, A. C., \& Romero, F. (2017). A review of the meanings and the implications of the Industry 4.0 concept. Procedia Manufacturing, 13, 1206-1214.

Rajbhandari, S., Khanal, G., Parajuli, S., \& Karki, D. (2020). A Review on Potentiality of Industry 4.0 in Nepal: Does the Pandemic Play Catalyst Role?. Quest Journal of Management and Social Sciences, 2(2), 366-379. 
Schmidt, M. Möhring, R.-C. Härting, C. Reichstein, P. Neumaier, and P. J. (2015). Industry 4.0: Towards future industrial opportunities and Challenges. Lecture Notes in Business Information Processing, 208, 16-27.

Schneider, P. (2018). Managerial challenges of Industry 4.0: an empirically backed research agenda for a nascent field. Review of Managerial Science, 12(3), 803-848.

Schuh, G., Potente, T., Wesch-Potente, C., Weber, A. R., \& Prote, J. P. (2014). Collaboration Mechanisms to increase Productivity in the Context of Industrie 4.0. Procedia Cirp, 19, 51-56.

Yang, C. H., \& Shyu, J. Z. (2009). Cross-national and cross-industrial comparison of two strategy approaches for global industrial evolution. Technological Forecasting and Social Change, 76(1), 2-25.

Zhou, K., Liu, T., \& Zhou, L. (2016). Industry 4.0: Towards future industrial opportunities and challenges. 2015 12th International Conference on Fuzzy Systems and Knowledge Discovery, FSKD 2015, 2147-2152. https://doi.org/10.1109/FSKD.2015.7382284

\section{Copyrights}

Copyright for this article is retained by the author(s), with first publication rights granted to the journal.

This is an open-access article distributed under the terms and conditions of the Creative Commons Attribution license (http://creativecommons.org/licenses/by/4.0/) 